\title{
La impronta de la memoria en el cómic latinoamericano
}

\section{The print of memory in the Latin American comic}

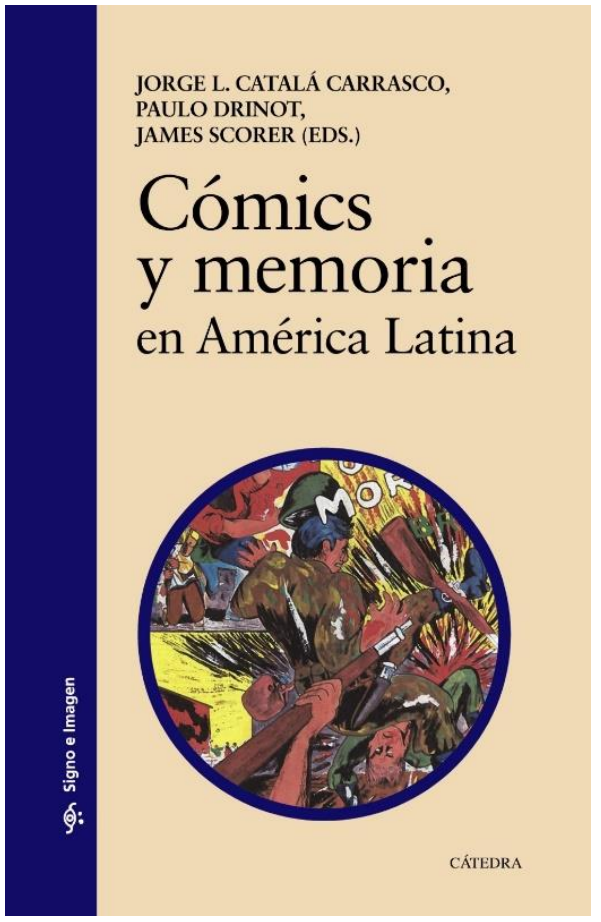

Reseña de: Catalá Carrasco, J. L., DrinOt, P. y SCORER, J. (eds.), Cómics y memoria en América Latina, Madrid, Ediciones, Cátedra, 2019.

\section{David García-Reyes}

Profesor visitante en la Facultad de Humanidades y Arte de la Universidad de Concepción (Chile) mangarcia@udec.cl

Código ORCID: https://orcid.org/0000-0003-34451304

Referencia: GARCÍA-REYES, D., «La impronta de la memoria en el cómic latinoamericano», Neuróptica. Estudios sobre el cómic, segunda época, 2, Zaragoza, Prensas de la Universidad de Zaragoza, 2020, pp. 271-276.

La paulatina importancia de los estudios de cómic en Iberoamérica desde hace dos décadas se ve reflejada en la producción teórica precedente. La importancia de diversos ensayos entre los que se pueden citar el ya clásico $L a$ España del tebeo. La historieta española de 1940 a 2000 (Espasa Calpe, 2001) de Antonio Altarriba o dos obras fundamentales de Ana Merino abordando la cuestión del cómic en español: El cómic hispánico (Cátedra, 2003) y Diez ensayos para pensar el cómic (EOLAS/Universidad de León, 2017). En esta línea viene a situarse Cómics y memoria en América Latina, editado por Jorge L. Catalá Carrasco, Paulo Drinot y James Scorer, una obra fundamental para indagar en torno a las representaciones del cómic desde modalidades que abarcan desde la reflexión histórica al cuestionamiento de lo identitario en Latinoamérica. El texto ya estaba disponible con anterioridad, puesto que 
apareció originalmente editado en inglés como Comics \& Memory in Latin America (University of Pittsburgh Press, 2017) y desde finales del año 2019 está disponible su versión española. El ensayo recoge las aportaciones de ocho académicos, que señalan algunas de las tendencias que los trabajos sobre la representación de la memoria y el recuerdo van significando en la disciplina. Específicamente, el libro aborda investigaciones y análisis en torno a la narración figurativa latinoamericana desde perspectivas versátiles en las que confluyen los estudios culturales y los estudios de cómic. De forma sucinta, aunque el título reseñado abarque más de lo que cualquier volumen puede ofrecer, la obra proyecta una visión panorámica muy ilustrativa en la que convergen distintas escuelas y tradiciones académicas. Tal vez por esa voluntaria y asumida diversidad, se echa de menos mayor presencia de otras propuestas originadas desde América Latina, pero es obvio que poder alcanzar una representatividad en un tema tan variado puede resultar una aspiración demasiado ideal cuando pensamos en las prescripciones del mundo editorial.

La introducción de Cómics y memoria en América Latina es un ejercicio de síntesis en el que se aporta un enfoque general de los estudios y de la teorización de las representaciones de la memoria histórica en la región desde los ámbitos de la historiografía y la sociología de la historieta. Por ello, cuando se aborda la cuestión de la memoria se recurre a la producción en este ámbito de pensadores como Maurice Halbwachs o Andreas Huyssen. La importancia de los discursos de memoria vinculados a procesos globales de descolonización, junto al surgimiento y auge de distintos movimientos sociales no son ajenos a la realidad del cómic latinoamericano y así se ve reflejado en muchos segmentos del libro. Si se piensa por ejemplo en obras del cómic europeo y norteamericano con propuestas temáticas en torno al Holocausto u otros genocidios más recientes en el tiempo como el de Ruanda o los Balcanes, se puede verificar una conexión y una pulsión con lo que ofrece el cómic en América Latina. Algunas de las situaciones históricas sufridas en las jóvenes repúblicas latinoamericanas durante el siglo XX y el presente siglo, estimulan reflexiones completamente imbricadas en los procesos de judicialización y armonización de las tragedias sociales, políticas y económicas alumbradas durante la década de los setenta del siglo pasado. Sucesos traumáticos de enorme trascendencia histórica que de norte a sur cruzan Latinoamérica, desde la masacre de Tlatelolco (2 de octubre de 1968) a la feroz represión de las dictaduras del Cono Sur. De algún modo, muchas de las novelas gráficas realizadas en América Latina en el siglo XXI están signadas por el cambio de paradigma que supone la revisión de los procesos 
judiciales, sociales y culturales que buscan restituir la omisión de la memoria y contribuyen a repensar el recuerdo de sucesos de enorme impacto en cada una de las naciones latinoamericanas. Los ocho capítulos del ensayo tratan, desde la propia diversidad de la narración figurativa latinoamericana, cuestiones que están vinculadas a la memoria y abordan nociones como la identidad y la capacidad para reconstruir los sucesos históricos a partir del arte de la historieta. En el monográfico se subraya el valor del cómic como documento de expresión memorialística, donde las propias prácticas de la narración figurativa articulan discursos que enfrentan distintas esferas de la memoria histórica. El caso específico del cómic ofrece una evidente naturaleza autoral por parte de los artífices de los distintos textos analizados, a excepción de la propuesta colectiva del cómic educativo sandinista que se estudia en el cuarto capítulo.

En el primer capítulo, Jorge L. Catalá Carrasco se ocupa del cómic cubano La emboscada (1982), una obra de Ernesto Padrón y Orestes Suárez. En este estudio se resalta la importancia y el papel del pueblo cubano en el proceso de emancipación frente a la metrópoli española durante la guerra hispano-cubano-americana (1898). Esa toma de conciencia sería la idealización del proceso de independencia frente a España, operando como analogía para oponerse a nuevas formas de imposición neocolonial por parte de los Estados Unidos. Durante más de seis décadas, los políticos de Washington promovieron un sistema de injerencias en los distintos gobiernos de Cuba, junto con la posterior importancia del asedio a la isla tras el triunfo de la Revolución cubana en 1959. Catalá Carrasco examina la representación de la obra y reflexiona en cómo la narración gráfica de Padrón y Suárez proyecta y difunde usos y costumbres de finales del siglo XIX como la vestimenta, las armas o las estrategias militares, enfatizando el valor escenográfico y documental del cómic a la hora de representar los espacios de la memoria histórica. Catalá Carrasco subraya las virtudes de la historieta en su representación de detalles en los que prima el rigor de la ambientación y la voluntad de verosimilitud a la que todo relato aspira. Al mismo tiempo, el capítulo se plantea el debate y la reflexión en torno a la construcción de los mitos nacionales cubanos y a muchas de las necesarias redefiniciones que implica asumir la importancia que tanto la propaganda como el discurso oficial del poder, intentan imponer para erigirse en axiomas inamovibles e inalterables.

En el segundo capítulo, Edoardo Balletta ahonda en la vinculación política de Hugo Germán Oesterheld, el más reputado guionista del cómic 
argentino y uno de los mayores maestros de la historieta iberoamericana. A partir de dos de las últimas obras de Oesterheld, Latinoamérica y el imperialismo: 450 años de guerra (1973-1974) con arte de Leopoldo Durañona y La guerra de los Antartes (1970) con grafismo de Gustavo Trigo, Balleta ofrece un estudio pormenorizado en torno a los rasgos políticos e ideológicos del autor argentino en la última etapa de su producción. En ambas obras se hace muy evidente la militancia de Oesterheld en Montoneros, una de las facciones más combativas y progresistas del peronismo argentino. No es de extrañar, por tanto, que la serie de historietas de Latinoamérica y el imperialismo apareciese en El Descamisado, semanario peronista de izquierda. El compromiso político de Oesterheld junto a sus cuatro hijas les convirtió en desparecidos y víctimas de la brutal y feroz represión de la última dictadura argentina. El segmento de Balleta resulta enormemente útil para entender cómo el guionista entendía la historieta como un arma para la denuncia política de los abusos que se estaban produciendo en la Argentina en particular y en América Latina en general. Por eso fuera en clave historiográfica como Latinoamérica y el imperialismo o planteando un relato de ciencia-ficción distópica ambientado en la Antártida, Oesterheld tuvo muy presente el mundo y la sociedad en la que vivía para armar ambas obras.

En el capítulo tres, Isabella Cosse recorre la significación social y política de Mafalda dentro del contexto posterior al fin de su publicación como tira cómica regular en 1973 en la prensa argentina. La creación de Joaquín Salvador Lavado «Quino» no solamente se convirtió en un referente crítico y moral en su contexto de producción, pues ha conseguido perpetuarse a lo largo del tiempo en sus lúcidas e irónicas reflexiones sobre el ser humano. Con el retorno de la democracia argentina tras la dictadura, la proyección de Mafalda crece dentro del contexto latinoamericano y, además, traspasa geografías y lenguas para constituirse a nivel global como un símbolo del espíritu crítico.

Christiane Berth en el capítulo cuatro reflexiona sobre las distintas campañas de educación y memoria colectiva con el cómic como protagonista. Berth detalla la promoción de la lectura y la cultura en estas acciones, que fueron llevadas a cabo por el proyecto sandinista en Nicaragua tras la revolución que acabó con el régimen de Anastasio Somoza.

En el quinto capítulo Paulo Drinot analiza la versión digital de El Cuy, continuación de la tira cómica más famosa del historietista peruano Juan Acevedo. Drinot observa la significación de la producción de Acevedo y la importancia de ésta para pensar en la situación política del Perú entre los años 
setenta y ochenta del siglo XX. El blog historietístico redimensiona cuestiones medulares de la evolución de la izquierda peruana y se establece como un espacio virtual de memoria, operando como un medio que moviliza y alienta el debate. Como señala el académico peruano, la web de $E l$ Cuy sirve para mostrarnos no solamente las atrocidades de la insurgencia de Sendero Luminoso, sino la guerra sucia del estado para acabar con esta organización maoísta y con toda resistencia o subversión, estrategias represivas que serán recurrentes a lo largo y ancho de América Latina.

Cyntia E. Milton retoma muchos de los temas de Drinot y ahonda en el tratamiento del conflicto peruano por parte de la novela gráfica Rupay, publicada en 2008. En la mencionada obra secuencial se aprecia una redefinición de la memoria y de la diversidad de puntos de vista para poder acercarse a algo parecido a la verdad.

En el capítulo siete James Scorer analiza Road Story (2007), comercializada como la primera novela gráfica chilena ${ }^{1}$, es obra de Gonzalo Martínez, que adapta a la historieta un cuento de Alberto Fuguet. El escritor chileno, considerado como un ejemplo de literato ajeno en su obra a las realidades histórica, social y política chilenas, a menudo ha sido descrito como un creador mitómano muy influido por el american way of life y lo mainstream. La consideración anterior es tan reductiva como incompleta. Igualmente, queda desvirtuada con el trabajo de Martínez, en el que el historietista chileno sabe ejecutar una obra en la que los espacios vacíos de indeterminación del texto literario convergen y aportan una visión en la que Scorer percibe y señala algunas de las suturas no cerradas durante la transición política de la dictadura a la democracia en el país transandino. La novela gráfica es una historia de carretera y un viaje desde Estados Unidos a México, aparentemente carece de una significación política o una incursión directa en la memoria histórica, pero lo sutil es frecuente tanto en Fuguet como en Martínez. En lo formal, la trama es deudora de On the Road (1957) de Jack Kerouac o del filme Easy Rider (1969) de Dennis Hopper. En el ensayo sobre Road Story se detalla un sugestivo análisis sobre lo postcolonial y la importancia de Estados Unidos en el desarrollo de la región. Scorer suministra acertadas reflexiones sobre las políticas económicas neoliberales y la reestructuración del estado a partir de la citada novela gráfica. Las mencionadas políticas clausuran cualquier tipo de estructura que beneficie al

1 Reconocimiento que debería recaer en Lebbeus Rahn, obra de Martín Cáceres que fue publicada en 1992. 
conjunto de la sociedad chilena y por extensión, la ambición de que el mismo esquema se imponga en el conjunto de América Latina.

En el último capítulo, Edward King indaga en las conexiones entre lo literario y lo iconográfico, entre lo discursivo y lo técnico a partir de la novela gráfica Morro da Favela (2011) de André Diniz. La narración brasileña dialoga con las formas de representar y narrar secuencialmente la unión entre la favela - en el contexto urbano- y el sertão - espacio del interior rural brasileño-. Estas correspondencias permiten visualizar lo formal y lo estético, pero también facilitan una visión de lo popular en estos dos ámbitos tan presentes en la historia brasileña, junto a su confluencia en una enorme galería de imágenes del gigante sudamericano.

El conjunto de ensayos resulta muy valioso para los investigadores del cómic en Iberoamérica. Lo que se echa de menos es una coda a modo de cierre y la inclusión de un estudio centrado en problemáticas o representaciones de la memoria dentro de la historieta mexicana. Desde un punto de vista regional y del mismo modo que no se puede pensar América Latina sin Brasil, tampoco se puede contemplar la dimensión de lo latinoamericano sin México. No obstante, se debe reconocer el esfuerzo y la destacada contribución de los artífices de Cómics y memoria en América Latina. La obra es significativa y se debe reivindicar su importante aportación dentro de los estudios de cómic, ofreciendo perspectivas diversas y muy fecundas que iluminan y señalan muchos de los caminos por recorrer en la investigación sobre la historieta en Iberoamérica. 